OPEN ACCESS

Edited by: Jan Potempa, University of Louisville, United States

Reviewed by:

Oleh Andrukhov, University Dental Clinic Vienna, Austria Ann Progulske-Fox University of Florida, United States

*Correspondence: Xiaolin Tang xltang@cmu.edu.cn

Specialty section: This article was submitted to

Bacteria and Host,

a section of the journal

Frontiers in Cellular and Infection Microbiology

Received: 13 May 2020 Accepted: 21 September 2020 Published: 15 October 2020

Citation:

Yang X, Niu L, Pan Y, Feng X, Liu J, Guo $Y$, Pan $C$, Geng $F$ and Tang $X$

(2020) LL-37-Induced Autophagy Contributed to the Elimination of Live Porphyromonas gingivalis Internalized

in Keratinocytes.

Front. Cell. Infect. Microbiol.

10:561761

doi: 10.3389/fcimb.2020.561761

\section{LL-37-Induced Autophagy Contributed to the Elimination of Live Porphyromonas gingivalis Internalized in Keratinocytes}

\author{
Xue Yang ${ }^{1,2}$, Li Niu 1,2, Yaping Pan 1,2, Xianghui Feng ${ }^{3}$, Jie Liu' ${ }^{4}$, Yan Guo ${ }^{2,5}$, Chunling Pan ${ }^{1,2}$, \\ Fengxue Geng ${ }^{1,2}$ and Xiaolin Tang ${ }^{1,2 *}$ \\ 1 Department of Periodontology, School and Hospital of Stomatology, China Medical University, Shenyang, China, ${ }^{2}$ Liaoning \\ Provincial Key Laboratory of Oral Diseases, School of Stomatology, China Medical University, Shenyang, China, ${ }^{3}$ Department \\ of Periodontology, Peking University School and Hospital of Stomatology, Beijing, China, ${ }^{4}$ Center of Science Experiment, \\ China Medical University, Shenyang, China, ${ }^{5}$ Department of Oral Biology, School of Stomatology, China Medical University, \\ Shenyang, China
}

Porphyromonas gingivalis ( $P$. gingivalis), one of the most important pathogens of periodontitis, is closely associated with the aggravation and recurrence of periodontitis and systemic diseases. Antibacterial peptide LL-37, transcribed from the cathelicidin antimicrobial peptide (CAMP) gene, exhibits a broad spectrum of antibacterial activity and regulates the immune system. In this study, we demonstrated that LL-37 reduced the number of live $P$. gingivalis (ATCC 33277) in HaCaT cells in a dose-dependent manner via an antibiotic-protection assay. LL-37 promoted autophagy of HaCaT cells internalized with $P$. gingivalis. Inhibition of autophagy with 3-methyladenine (3-MA) weakened the inhibitory effect of LL-37 on the number of intracellular $P$. gingivalis. A cluster of orthologous groups (COGs) and a gene ontology (GO) functional analysis were used to individually assign $65(10 \%)$ differentially expressed genes (DEGs) to an "Intracellular trafficking, secretion, and vesicular transport" cluster and 306 (47.08\%) DEGs to metabolic processes including autophagy. Autophagy-related genes, a tripartite motif-containing 22 (TRIM22), and lysosomal-associated membrane protein 3 (LAMP3) were identified as potentially involved in LL-37-induced autophagy. Finally, bioinformatics software was utilized to construct and predict the protein-protein interaction (PPI) network of CAMP-TRIM22/LAMP3-Autophagy. The findings indicated that LL-37 can reduce the quantity of live $P$. gingivalis internalized in $\mathrm{HaCaT}$ cells by promoting autophagy in these cells. The transcriptome sequencing and analysis also revealed the potential molecular pathway of LL-37-induced autophagy.

Keywords: Porphyromonas gingivalis, internalization, LL-37, autophagy, keratinocytes, transcriptome sequencing

\section{INTRODUCTION}

Porphyromonas gingivalis ( $P$. gingivalis), a keystone periodontal pathogen, is a Gram-negative bacterium with a variety of virulence factors (Shah and Collins, 1988). It is closely associated with the aggravation and relapse of periodontitis (Socransky and Haffajee, 1992; Grossi et al., 1995; Holt and Ebersole, 2005). The epithelium of oral mucosa can be divided into keratinized and 
non-keratinized mucosa. Keratinized epithelium consists of keratinocytes, such as gingival epithelium. These epithelial tissues are the first defense against bacterial invasion. $P$. gingivalis can invade epithelial cells widely (Yilmaz et al., 2006). It has even been found that $P$. gingivalis can regulate the cell cycle process and the expression of inflammatory factors after it is internalized in immortalized gingival epithelial cells (Pan et al., 2014). Moreover, it has a potential impact on the malignant transformation of gingival epithelial cells (Chang et al., 2019a,b; Geng et al., 2019). In addition, $P$. gingivalis can cause a latent case of human immunodeficiency virus-1 (HIV-1) and mediate HIV-1 in Hela epithelial cells, also a kind of keratinocyte (Imai et al., 2009; Mantri et al., 2014). Therefore, it is important to kill $P$. gingivalis when it is internalized in keratinocytes. Broad-spectrum antibiotics used for this purpose have many side effects, such as dysbacteriosis and antibiotic resistance (Soares et al., 2012). As a common drug used to inhibit anaerobes, metronidazole cannot penetrate into mammalian cells to inhibit intracellular bacteria (Eick et al., 2004; Löfmark et al., 2010). As such, effective drugs that can inhibit intracellular $P$. gingivalis with minimal side effects must be identified urgently.

Autophagy is the process whereby cells phagocytize their own organelles or cytoplasm and finally degrade cargos in lysosomes (Weidberg et al., 2011). It plays a vital role in stress response, immune defense, and homeostasis, and it is an important defense against invading microorganisms (Sanjuan and Green, 2008; Lapierre et al., 2011). Studies have indicated that $P$. gingivalis can promote autophagy in THP-1 cells, suggesting that autophagy can also promote the clearance of $P$. gingivalis in phagocytes (Park et al., 2017). Lamont et al. (1995) found that $P$. gingivalis mainly existed in a free state in gingival epithelial cells. Our previous study found that $P$. gingivalis mainly existed in a free state, but it was enclosed by incomplete autophagosomes in $\mathrm{KB}$ cells, a type of Hela cell subline, suggesting that $P$. gingivalis may escape capture by autophagy and promote the formation of incomplete autophagosomes in epithelial cells through some mechanism (Hu et al., 2019). Furthermore, drugs that can regulate autophagy process may help eliminate intracellular $P$. gingivalis. However, the molecular mechanism of the effects of autophagy on $P$. gingivalis in epithelial cells remains unknown.

Human cationic antimicrobial peptide-18 (hCAP18) is the only antimicrobial peptide (AMP) in the cathelicidins family found in the human body that is transcribed from the human cathelicidin antimicrobial peptide $(C A M P)$ gene. It is the precursor of LL-37, which mainly exists in neutrophils and monocyte macrophages (Vandamme et al., 2012). LL-37 exhibits broad-spectrum antibacterial activity against Gram-positive and Gram-negative bacteria, fungi, and envelope viruses (Larrick et al., 1995; Dorschner et al., 2001; Hase et al., 2003; Wang et al., 2008). LL-37 protein contains hydrophobic N-terminal

\footnotetext{
Abbreviations: $P$. gingivalis, Porphyromonas gingivalis; hCAP18, human cationic antimicrobial peptide-18; NF- $\mathrm{B}$, nuclear factor-kappa B; MAPK, mitogenactivated protein kinase; $\mathrm{BHI}$, brain heart infusion; CFU, colony forming unit; MOI, multiplicity of infection; qRT-PCR, quantitative real time-polymerase chain reaction; GO, gene ontology; KEGG, kyoto encyclopedia of genes and genomes; COG, cluster of orthologous group; TRIM22, tripartite motif-containing 22; LAMP3, lysosomal-associated membrane protein 3.
}

and hydrophilic C-terminal (Burton and Steel, 2009), and it can bind and neutralize lipopolysaccharide (LPS) and destroy the cell wall of bacteria, thus demonstrating a direct antibacterial effect (Larrick et al., 1995; Turner et al., 1998). Apart from this effect, LL-37 has been shown to antagonize intracellular Mycobacterium by promoting autophagy in macrophages. Rekha et al. (2015) found that endogenous LC3 could be co-localized with hCAP18/LL-37 in autophagosomes to induce autophagy and limit the growth of Mycobacterium tuberculosis in macrophages. Yuk et al. (2009) found that LL-37 could induce autophagy in human monocytes, promote the expression of the autophagy-related proteins Beclin-1 and LC3, and induce the colocalization of Mycobacterium tuberculosis with autophagosomes in cells. In addition, Wan et al. (2018) found that LL-37 could inhibit the number of Mycobacterium tuberculosis in macrophages by promoting autophagy. However, it has been rarely reported whether LL-37 can help eliminate bacteria in keratinocytes, such as gingival epithelial keratinocytes. In addition, it is not clear whether LL-37 participates in the elimination of intracellular $P$. gingivalis in keratinocytes.

In this study, we used the human immortalized epidermal keratinocyte HaCaT cell line as a study model. These cells share similar morphological characteristics with gingival epithelial cells and have been frequently used as study models of gingival epithelial cells (de Camargo Pereira et al., 2013; Kidwai et al., 2013; Kim et al., 2018). The purpose of this study was to investigate the effect of LL-37 on $P$. gingivalis internalized in $\mathrm{HaCaT}$ cells, the possible role of autophagy, and the potential molecular pathway during this process. The findings of the present study may provide new clues for the clearance of $P$. gingivalis in gingival keratinocytes.

\section{MATERIALS AND METHODS}

\section{Antibodies, Chemicals, and Plasmids}

The primary antibodies for LC3B (14600-1) and GAPDH (10494-1) were from Proteintech (Rosemont, USA). LL-37 (ab180760) and Anti-SQSTM1/p62 (ab207305) were from Abcam (Massachusetts, USA). The DyLight 800-labeled secondary antibody (A23220) was from Abbkine (California, USA). In addition, 3-Methyladenine (3-MA) was purchased from Selleck (Texas, USA). Transfection reagents GoldenTran-D were purchased from Golden Trans Technology (Jilin, China). The transient plasmid containing CAMP cDNA and the empty vector were from Genepharma (Suzhou, China).

\section{Bacteria and Bacterial Culture}

The $P$. gingivalis ATCC 33277 strain was originally obtained from the American Tissue Culture Collection (Maryland, USA) and stored at the Department of Oral Biology at China Medical University. The bacteria were maintained anaerobically at $37^{\circ} \mathrm{C}$ on brain-heart-infusion (BHI) Ager medium plates, supplemented with $5 \%$ sterilized and defibrinated sheep blood, $0.5 \%$ hemin, and $0.1 \%$ Vitamin $\mathrm{K}$. All bacterial culture reagents were purchased from Aoboxing Bio-tech (Beijing, China). Then, $P$. gingivalis was cultured in a liquid BHI medium for 16$18 \mathrm{~h}$. An optical density of 1.0 at $600 \mathrm{~nm}$ (NanoDrop2000, Keyu 
Xingye Technology Development Co., Ltd., Beijing, China) for $P$. gingivalis was determined to correlate to $10^{9}$ bacteria/mL.

\section{Cell Lines and Cell Culture}

The human keratinocyte cell line $\mathrm{HaCaT}$ was obtained from the Cell Resource Center at the Institute of Basic Medical Sciences, CAMS/PUMC (Beijing, China). HaCaT cells were maintained in $\alpha$-MEM supplemented with $10 \%$ fetal bovine serum (FBS) under the conditions of $37^{\circ} \mathrm{C}$ with $5 \% \mathrm{CO}_{2}$. Upon reaching $80 \%$ confluent growth, the $\mathrm{HaCaT}$ cells were dissociated with $0.05 \%$ trypsin-EDTA and resuspended by gentle pipetting in fresh complete media. In addition, $0.05 \%$ trypsin-EDTA was purchased from Gibco Laboratories (NY, USA), and the other cell culture regents were purchased from HyClone Laboratories (Logan, UT, USA).

\section{Establishment of the $P$. gingivalis Internalized $\mathrm{HaCaT}$ by an Antibiotic Protection Assay}

A bacterial internalization model was established by an antibiotic protection assay (Lamont et al., 1995). The HaCaT cells were infected with $P$. gingivalis with a specific multiplicity of infection (MOI) for $6 \mathrm{~h}$ in antibiotic-free $\alpha$-MEM. Then, cells were washed three times with sterile Phosphate Buffered Saline (PBS, Hyclone, Logan, UT, USA) and were further incubated in the fresh culture medium containing $300 \mu \mathrm{g} / \mathrm{ml}$ of gentamicin and $200 \mu \mathrm{g} / \mathrm{ml}$ of metronidazole (Sigma, St. Louis, MO, USA) for an additional $1.5 \mathrm{~h}$.

\section{Transfection Assays}

For transfection, the HaCaT cells were plated on six-well, flatbottom plates at a seeding density of $3 \times 10^{5}$, and grown to $80 \%$ confluence. For transient overexpression of LL-37, the LL37 plasmid was transfected into HaCaT cells for $6 \mathrm{~h}$. An empty vector was used as the control. The instructions to complete cell transfection were followed. Then, we replaced the medium with fresh serum-free $\alpha$-MEM. The cells transfected with plasmids were used in subsequent experiments.

\section{Quantitative Real-Time Polymerase Chain Reaction}

Total RNA was extracted from cells using TRIzol reagent (Invitrogen Life Technologies, Gaithersburg, MD, USA) according to the manufacturer's instructions. Complementary DNA (cDNA) was then synthesized using $2 \mu \mathrm{g}$ of the total RNA according to the instructions in the reverse transcriptase kit (Takara Bio, Inc., Dalian, China). Real-time PCR analyses were conducted on an ABI Prism 7500 Sequence Detection System (Applied Biosystems, Foster City, CA, USA) in combination with a SYBR Premix Ex TaqTM II PCR Master Mix Reagents kit (Takara Bio, Inc., Dalian, China). Amplification was performed under the following cycling conditions: preincubation of $95^{\circ} \mathrm{C}$ for $30 \mathrm{~s}$ followed by 40 cycles at $95^{\circ} \mathrm{C}$ for $5 \mathrm{~s}$ and at $60^{\circ} \mathrm{C}$ for $34 \mathrm{~s}$. Primers were designed and synthesized by Shanghai Sango Biotech Co. Ltd. (Shanghai, China) (Table 1). The data for $P$. gingivalis $16 \mathrm{~S}$ rRNA were analyzed according to the absolute quantification method.
TABLE 1 | Primers used for real-time PCR.

\begin{tabular}{|c|c|}
\hline Primers & Sequences $\left(5^{\prime}-3^{\prime}\right)$ \\
\hline Porphyromonas & Forward Primer: AGGCAGCTTGCCATACTGCG \\
\hline gingivalis $16 \mathrm{~S}$ rRNA & Reverse Primer: ACTGTTAGCAACTACCGATG \\
\hline LL-37 & Forward Primer: TCGGATGCTAACCTCTACCG \\
\hline HIF1A-AS2 & $\begin{array}{l}\text { Reverse Primer: GGGTACAAGATTCCGCAAAA } \\
\text { Forward Primer: GATGGAAGCACTAGACAAAGTTCA } \\
\text { Reverse Primer: ATCAGTGGTGGCAGTGGTAGTG }\end{array}$ \\
\hline TRIM22 & $\begin{array}{l}\text { Forward Primer: CGACCTAATCGGCATCTGGCCA } \\
\text { Reverse Primer: CCTCGTITATGCGGAATGTITGGTG }\end{array}$ \\
\hline PRKCQ & $\begin{array}{l}\text { Forward Primer: TGGAAAGTGAGAGGGAAGGTITGC } \\
\text { Reverse Primer: GCTGAGAATGGGTGGATGGAAAGG }\end{array}$ \\
\hline LAMP3 & $\begin{array}{l}\text { Forward Primer: CCACACCCAACAACTCACAC } \\
\text { Reverse Primer: CTGGAAGGGTGGTCTGGTTA }\end{array}$ \\
\hline ATP6V1B1 & $\begin{array}{l}\text { Forward Primer: GCTGGACCTGAAGTCTCAGAGC } \\
\text { Reverse Primer: CCCAGGCCTGCTGTCTATCTC }\end{array}$ \\
\hline IGBP1-AS1 & $\begin{array}{l}\text { Forward Primer: GGCATCAACTTCTAACTCATCTCG } \\
\text { Reverse Primer: CTCATACCAGTCACTCACCGTCAT }\end{array}$ \\
\hline \multirow[t]{2}{*}{ GAPDH } & Forward Primer: GAAGGTGAAGGTCGGAGTC \\
\hline & Reverse Primer: GAAGATGGTGATGGGATITC \\
\hline
\end{tabular}

Furthermore, other data were analyzed according to relative quantification. The cycle threshold (Ct) of different genes was first normalized to GAPDH for the same sample, and fold changes were calculated through relative quantification $\left(2^{-\Delta \Delta \mathrm{Ct}}\right)$ as previously reported. Each experiment was performed in triplicate.

\section{Western Blotting}

The HaCaT cells were lysed with an RIPA lysis buffer supplemented with $1 \mathrm{mM}$ PMSF. The protein concentration was quantified using the BCA reagent (Beyotim, P0012, Shanghai, China). Proteins were separated by SDS-polyacrylamide gel electrophoresis (SDS-PAGE; Bio-Rad, Hercules, CA, USA) and transferred onto a PVDF membrane $(0.22 \mu \mathrm{m})$. The membranes were then incubated with primary antibodies (LC3B, p62, and LL-37) at $4^{\circ} \mathrm{C}$ overnight. GAPDH was used as the internal control. Membranes were incubated with the secondary antibody in the dark at $25^{\circ} \mathrm{C}$ for $60 \mathrm{~min}$. The images were obtained by the Infrared Fluorescence Scanning Imaging System (Odyssey CLx, LI-COR, USA). The density of the protein bands was measured and analyzed using Image J $1.52 \mathrm{v}$ software (NIH Image, Bethesda, MD, USA).

\section{High-Throughput Sequencing}

The mRNA sequencing and eukaryotic reference transcriptome analysis were further performed at Majorbio Technology Co., Ltd. (Shanghai, China) using the Illumina Novaseq 6000 platform (Illumina, San Diego, CA, USA).

\section{Analysis of Sequencing Data}

The raw data obtained from the high-throughput read were filtered using SeqPrep and Sickle software to remove connector contamination and low-quality and unknown reads. RSEM, Kallisto, and Salmon software were used to quantitatively analyze the expression levels of genes and transcripts. The FPKM, 

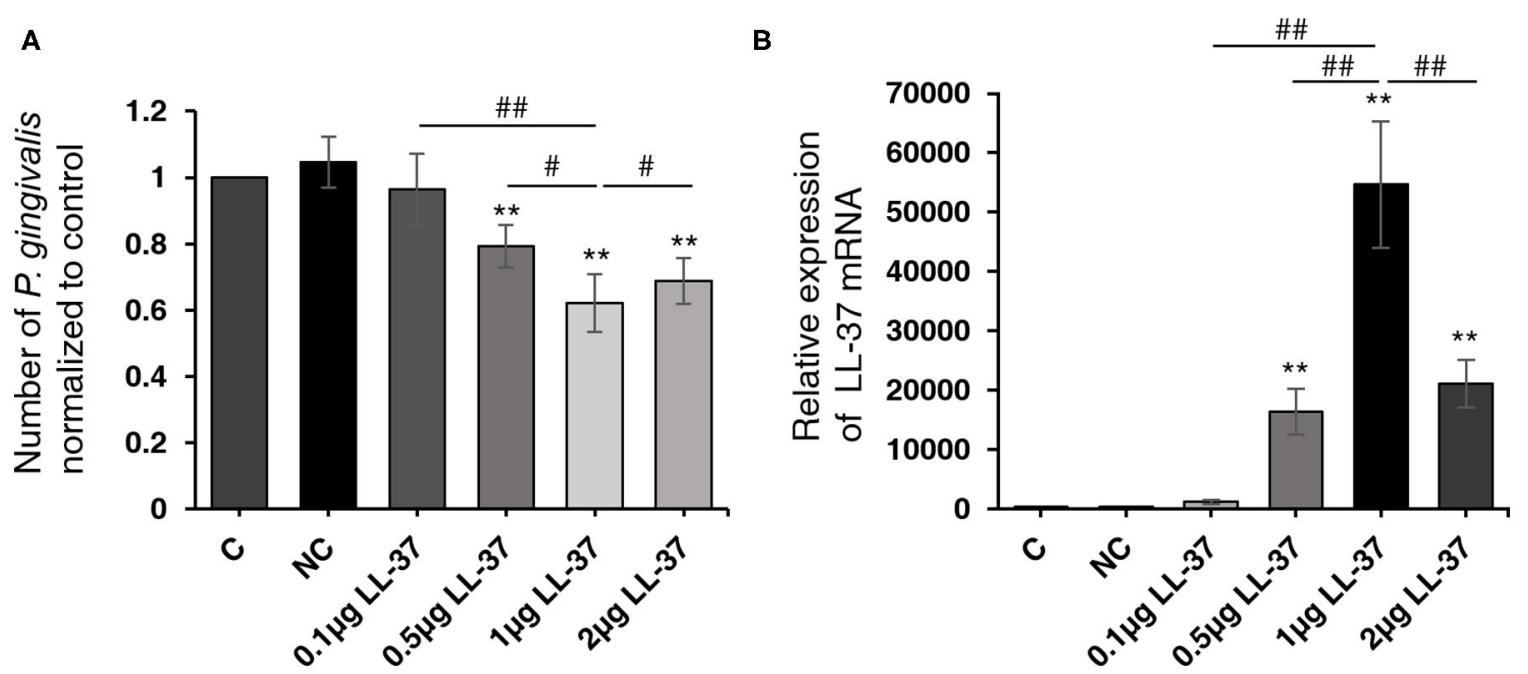

FIGURE 1 | LL-37 reduced the quantity of live Porphyromonas gingivalis internalized in HaCaT cells in a dose-dependent manner. HaCaT cells transfected with LL-37 plasmids $(0.1,0.5,1$, or $2 \mu \mathrm{g}, 6 \mathrm{~h})$ or empty vectors $(2 \mu \mathrm{g}, 6 \mathrm{~h})$ were internalized with Porphyromonas gingivalis (P. gingivalis, MOI $100,6 \mathrm{~h})$ using the antibiotic protection assay, and the total RNA was extracted after $18 \mathrm{~h}$. The number of $P$. gingivalis and the expression of LL-37 mRNA were detected with qRT-PCR. (A) The number of live $P$. gingivalis in HaCaT cells. (B) The relative expression of LL-37 mRNA in HaCaT cells. The data of $P$. gingivalis $16 S$ rRNA were analyzed according to the absolute quantification method. The data of LL-37 mRNA were analyzed according to the relatively quantification. Data presented as the mean \pm standard deviation $(n=3)$ relative to control are shown in bar graphs. C: untreated control, HaCaT cells that were not transfected; NC: negative control, HaCaT cells transfected with empty vectors; 0.1, 0.5, 1, or $2 \mu \mathrm{g} L \mathrm{~L}-37$ : HaCaT cells transfected with $0.1,0.5$, 1, or $2 \mu \mathrm{g}$ of LL-37 plasmids. ${ }^{* \star} P<0.01$, compared with the negative control. $\# P<0.05$ and $\# \# P<0.01$, compared with $1 \mu \mathrm{g}$ of LL-37 plasmids transfection.

TPM, and RPM methods were used to measure the level of expression. Differentially expressed genes (DEGs) were screened using DESeq2, DEGseq, and edgeR software (absolute value of fold change $\geq 2$, corrected $P<0.05$ ). Gene Ontology (GO) enrichment analysis of functionally significant terms in the GO database was applied using Goatools software and the Fisher exact test (corrected $P<0.05$ ) to find significantly enriched GO terms in DEGs by comparing them to the genome background. For the Kyoto Encyclopedia of Genes and Genomes (KEGG) pathway enrichment analysis, we mapped all of the DEGs to terms in the KEGG database (http://www.genome.jp/kegg/), looking for significantly enriched KEGG terms. We then analyzed the terms by Fisher's exact test using $\mathrm{R}$ script (corrected $P$ $<0.05$ ). Similarly, the Cluster of Orthologous Group (COG) analysis was performed in the COG database (http://www.ncbi. nlm.nih.gov/COG/).

\section{The Protein-Protein Interaction (PPI) Network Construction}

In order to further explore the interaction network of the CAMP with identified genes and identified genes with autophagy, the Network Data Exchange (NDEx, http://www. ndexbio.org/) was used to investigate the possible networks (Pratt et al., 2015; Pillich et al., 2017). NDEx is a searchable collection of gene expression and protein-protein interaction networks from multiple network and pathway databases, including the Biological General Repository for Interaction Datasets (BioGRID, https://thebiogrid.org/) (Oughtred et al., 2019), Human Integrated Protein-Protein Interaction Reference
(HIPPIE, http://cbdm-01.zdv.unimainz.de/ mschaefer/hippie/) (Alanis-Lobato et al., 2017), and Search Tool for the Retrieval of Interacting Genes (STRING, https://string-db.org/) (Szklarczyk et al., 2017). The Cytoscape software (version 3.8.0, http://www. cytoscape.org/), which integrates the CyNDEx App, was used to construct and visualize the PPI network (Shannon et al., 2003). The interaction was considered statistically significant when the combined score was $>0.4$.

\section{Statistical Analysis}

All of the data were expressed as the means \pm standard deviation (S.D.). Differences among the groups were analyzed by one-way analysis of variance (ANOVA) in the SPSS 22.0 software package (SPSS Inc., Chicago, IL, USA). For $p$ values, $P<0.05$ in comparison with the control was considered to be statistically significant. The data were representative of triplicate experiments.

\section{RESULTS}

\section{LL-37 Reduced the Quantity of Live $P$. gingivalis Internalized in $\mathrm{HaCaT}$ Cells in a Dose-Dependent Manner}

To investigate the effect of over-expressing LL-37 on the number of live $P$. gingivalis internalized in cells, HaCaT cells were transfected with a $2 \mu \mathrm{g}$ of empty vector and $0.1,0.5,1$, or $2 \mu \mathrm{g}$ of LL-37 plasmids for $6 \mathrm{~h}$ and then internalized with $P$. gingivalis (MOI 100, 6h) using the antibiotic protection assay. Total RNA was extracted after $18 \mathrm{~h}$. The qRT-PCR results 
A
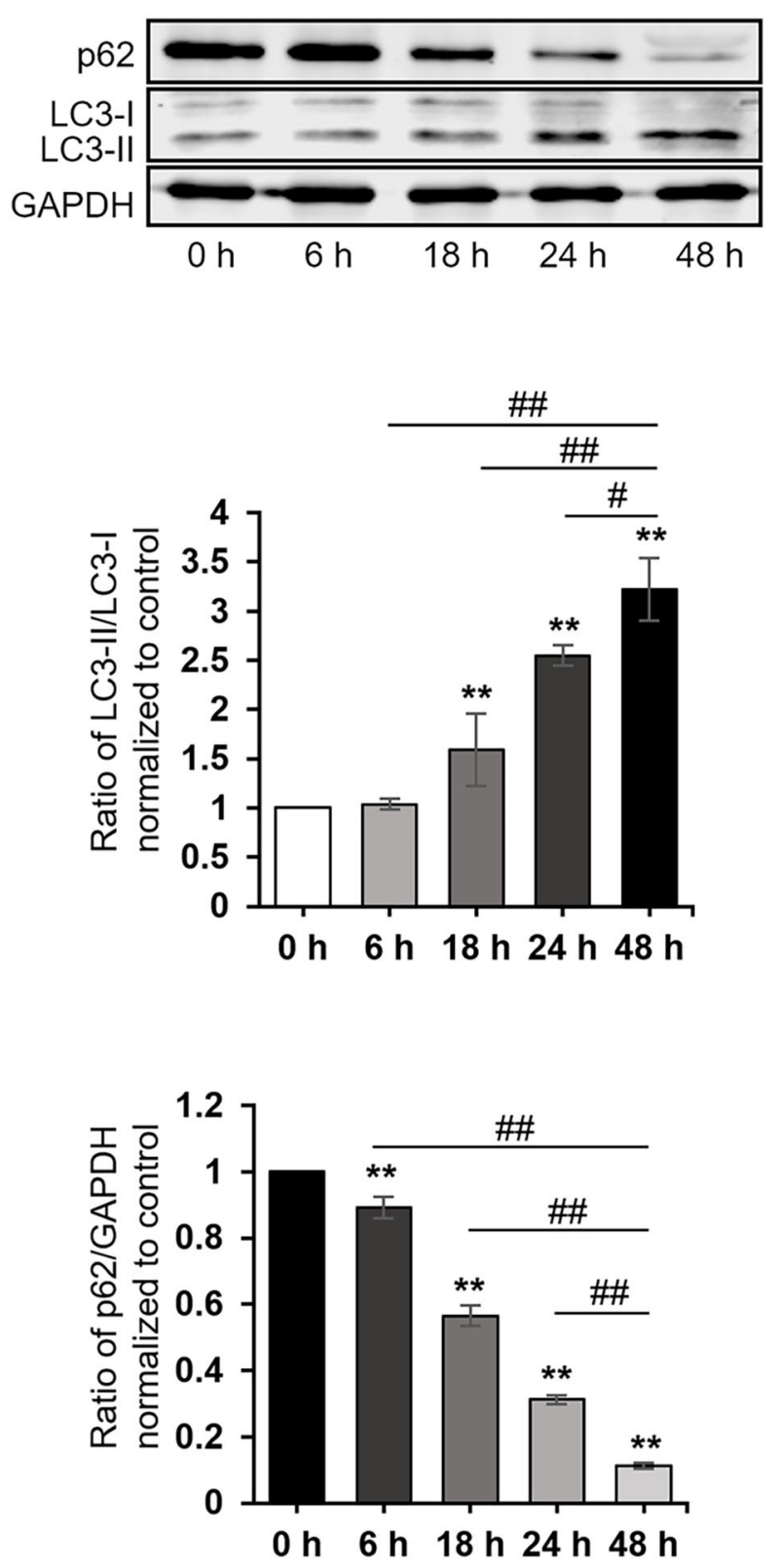

B

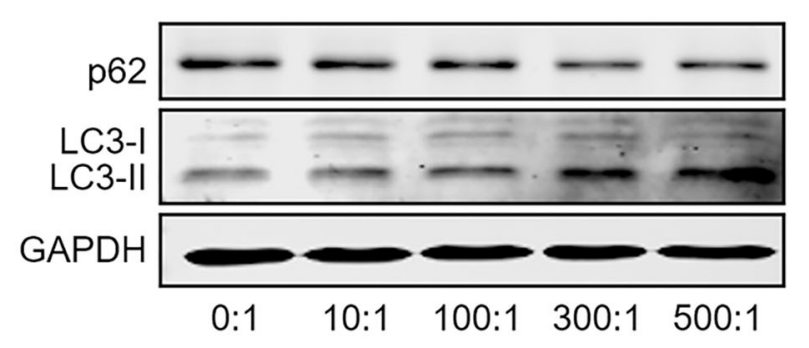

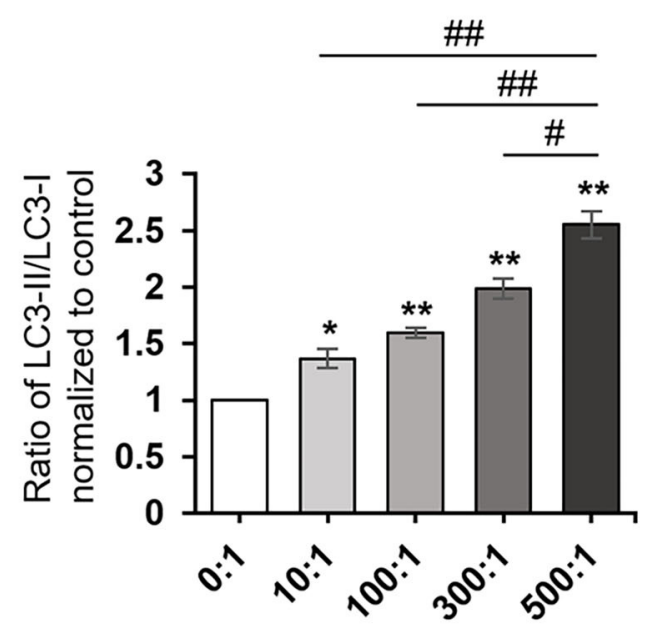

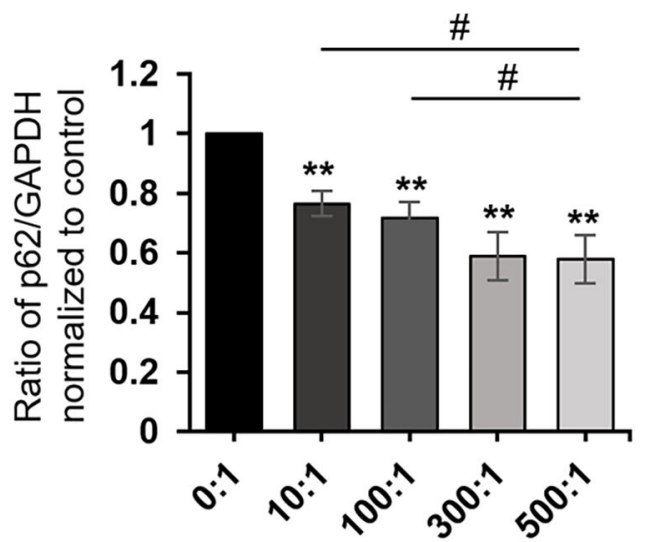

FIGURE 2 | Porphyromonas gingivalis internalization induced autophagy. The ratio of LC3-II/LC3-I, p62, and GAPDH were detected by a Western blot analysis of cell lysates from HaCaT cells treated as follows: (A) Taking $P$. gingivalis-internalized HaCaT cells (MOI 100, 6 h) by the antibiotic-protection assay as the starting point, the total protein was extracted after 0, 6, 18, 24, and 48h, respectively. (B) HaCaT cells were internalized with P. gingivalis (MOI 10-500, $6 \mathrm{~h}$ ) by the antibiotic protection assay, and the total protein was extracted after $18 \mathrm{~h}$. Protein-band density was analyzed using an $\mathrm{NIH}$ ImageJ software. Data presented as the mean \pm standard deviation $(n=3)$ relative to control are shown in bar graphs. ${ }^{*} P<0.05$ and ${ }^{\star *} P<0.01$, compared with control; $\# P<0.05$ and $\# \# P<0.01$, compared with $P$. gingivalis infection for $48 \mathrm{~h}$ (A) or $500 \mathrm{MOl}$ of $P$. gingivalis infection (B).

showed that compared with the control cells, the number of live $P$. gingivalis was significantly reduced $(P<0.01)$ by 0.79 , 0.62 , and 0.69 times in cells transfected with $0.5,1$, or 2 $\mu \mathrm{g}$ of LL-37 plasmids, respectively (Figure 1A). LL-37 mRNA expression gradually increased significantly as transfected with $0.1,0.5$, or $1 \mu \mathrm{g}$ of LL-37 plasmids, which was followed by a decrease and reached a peak in cells treated with $1 \mu \mathrm{g}$ of LL-37 plasmids (Figure 1B). 

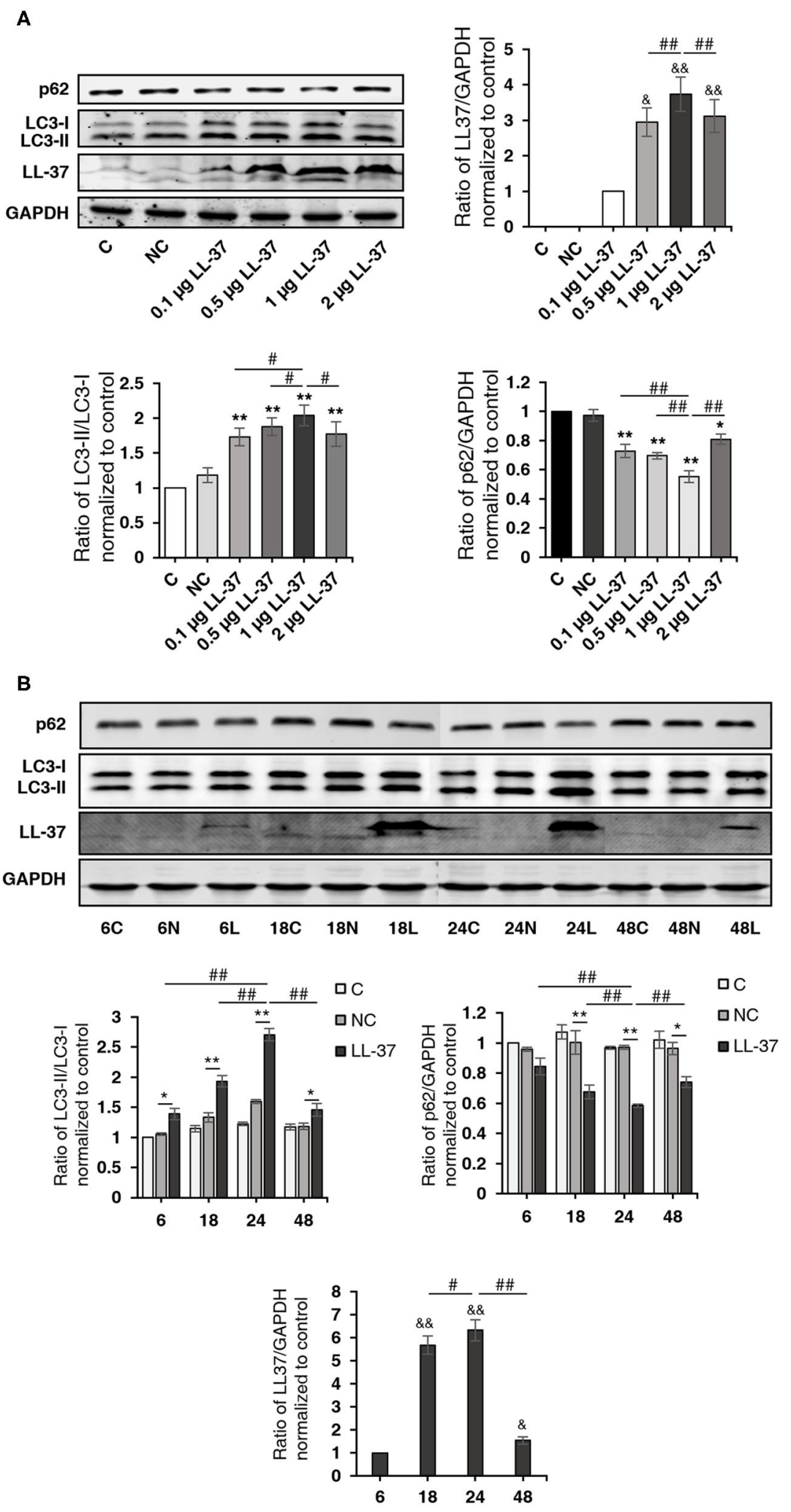

FIGURE 3 | LL-37 promoted autophagy. The ratio of LC3-II/LC3-I, p62, LL-37, and GAPDH were detected by a Western blot analysis of cell lysates from HaCaT cells transfected with (A) $0.1,0.5,1$, or $2 \mu \mathrm{g}$ of LL-37 plasmids or $2 \mu \mathrm{g}$ of empty vectors for $24 \mathrm{~h}$ or (B) LL-37 plasmids (1 $\mu \mathrm{g})$ or empty vectors (1 $\mu \mathrm{g})$ for $6-48 \mathrm{~h}$. 
FIGURE 3 | NC: negative control, HaCaT cells transfected with empty vectors. ${ }^{\star} P<0.05$ and ${ }^{* \star} P<0.01$, compared with negative control; \# $P<0.05$ and \#\# $P<$ 0.01 , compared with $1 \mu \mathrm{g}$ of LL-37 plasmids transfection for $24 \mathrm{~h}$; ${ }^{\&} P<0.05$ and ${ }^{\&} \& P<0.01$, compared with $0.1 \mu \mathrm{g} L \mathrm{~L}-37$ plasmids transfection (A) or LL-37 plasmids $(1 \mu \mathrm{g})$ transfection for $6 \mathrm{~h}$ (B).

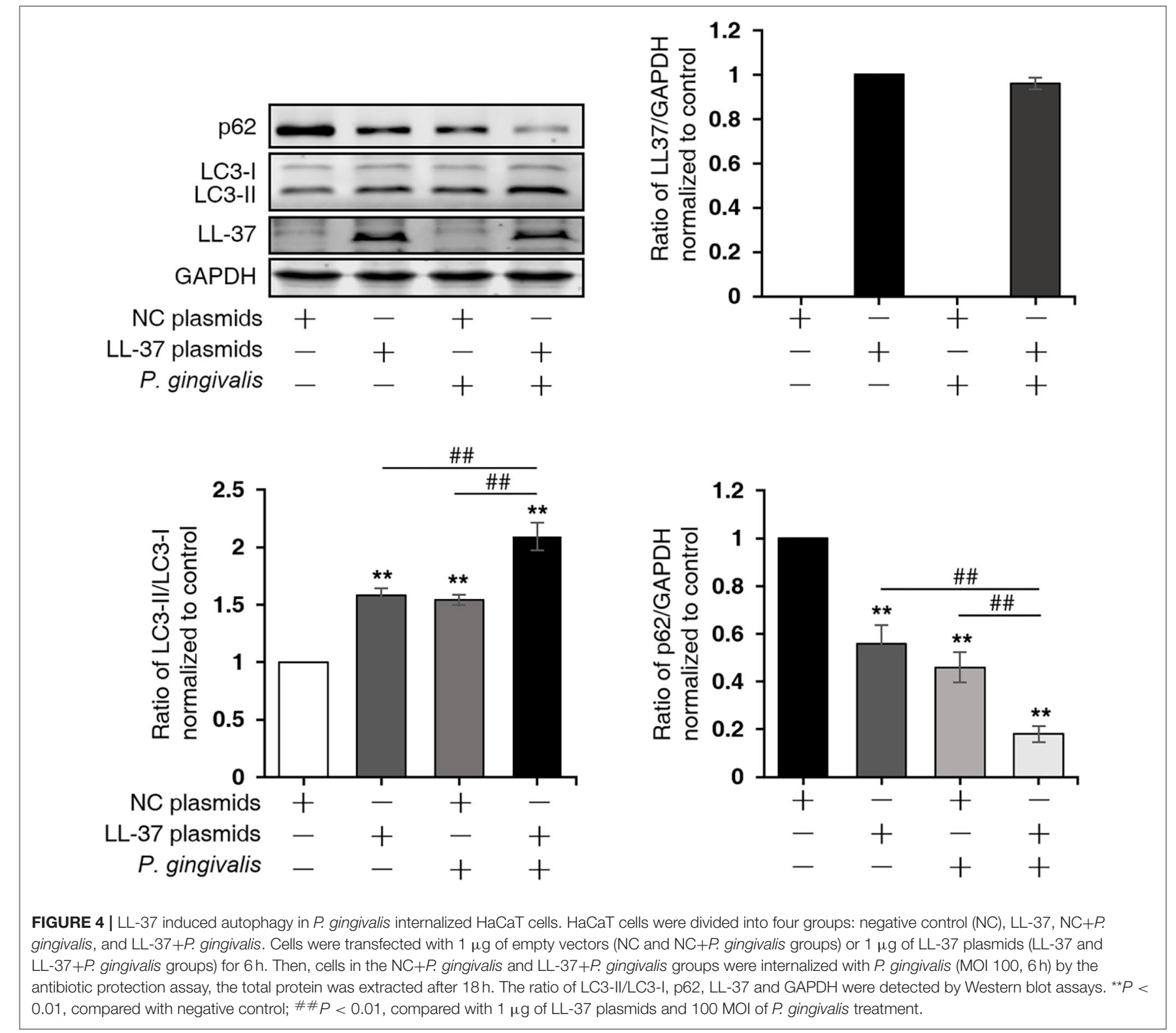

\section{$P$. gingivalis Internalization Induced Autophagy}

To explore whether $P$. gingivalis induces autophagy in cells, $\mathrm{HaCaT}$ cells were treated as follows: (A) Taking $P$. gingivalis internalized $\mathrm{HaCaT}$ cells (MOI 100, 6h) by the antibioticprotection-assay as the starting point, the total protein was extracted after $0,6,18,24$, and $48 \mathrm{~h}$. (B) HaCaT cells were internalized with $P$. gingivalis (MOI 10-500, 6h) using the antibiotic protection assay, and the total protein was extracted after $18 \mathrm{~h}$. Western blot assays demonstrated that $P$. gingivalis significantly increased the ratio of LC3-II/LC3-I and decreased the expression of p62 in $\mathrm{HaCaT}$ cells in a dose- and timedependent manner, where $P<0.01$ (Figures 2A,B).

\section{LL-37 Induced Autophagy}

To determine whether LL-37 induces autophagy in cells, HaCaT cells were transfected and treated with LL-37 plasmids $(0.1,0.5,1$, or $2 \mu \mathrm{g})$ for $24 \mathrm{~h}$ and LL-37 plasmids $(1 \mu \mathrm{g})$ for $6-48 \mathrm{~h}$. Western blot assays demonstrated that LL-37 significantly increased the ratio of LC3-II/LC3-I and decreased the expression of p62 in 


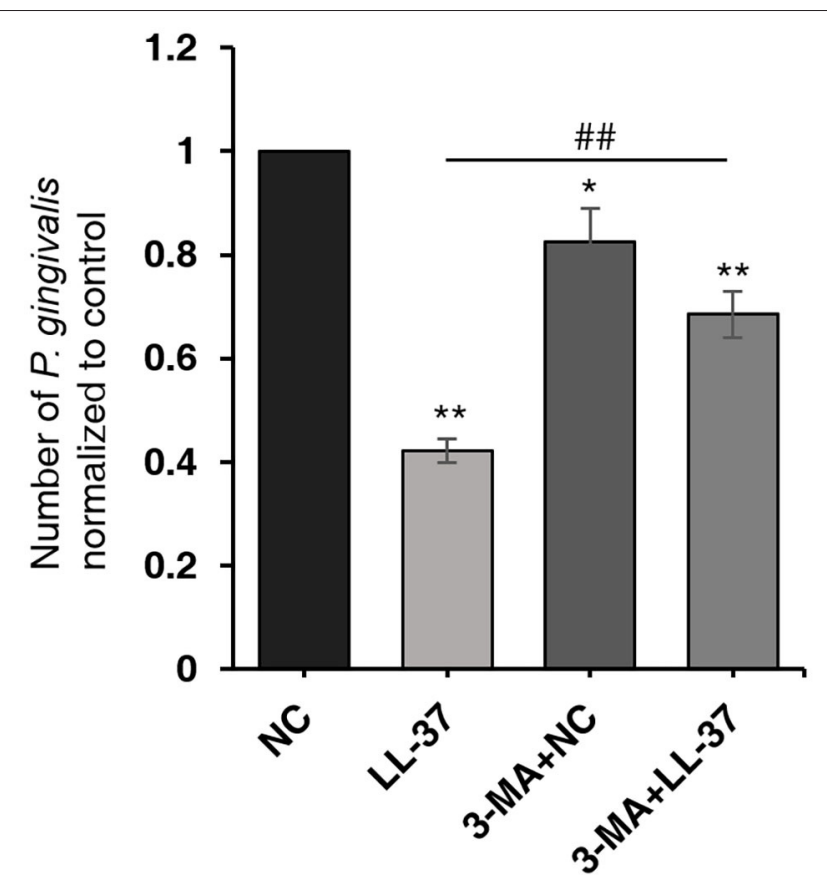

FIGURE 5 | Autophagy inhibition significantly decreased the antibacterial effect of LL-37. HaCaT cells were divided into four groups: NC, LL-37, 3-MA+NC, and 3-MA+LL-37. In the 3-MA+LL-37 and 3-MA+NC groups, the cells were pretreated with $3-\mathrm{MA}(10 \mathrm{mM}, 3 \mathrm{~h})$. Then, cells in the four groups that were transfected with LL-37 plasmids or empty vectors $(1 \mu \mathrm{g}, 6 \mathrm{~h})$ were internalized with $P$. gingivalis ( $\mathrm{MOI} 100,6 \mathrm{~h}$ ) using the antibiotic protection assay. The total RNA was then extracted after $18 \mathrm{~h}$. The qRT-PCR method was used to detect the numbers of live $P$. gingivalis in $\mathrm{HaCaT}$ cells. ${ }^{*} P<0.05$ and ${ }^{\star \star} P<0.01$, compared with negative control; $\# \# P<0.01$, compared with LL-37 plasmids treatment.

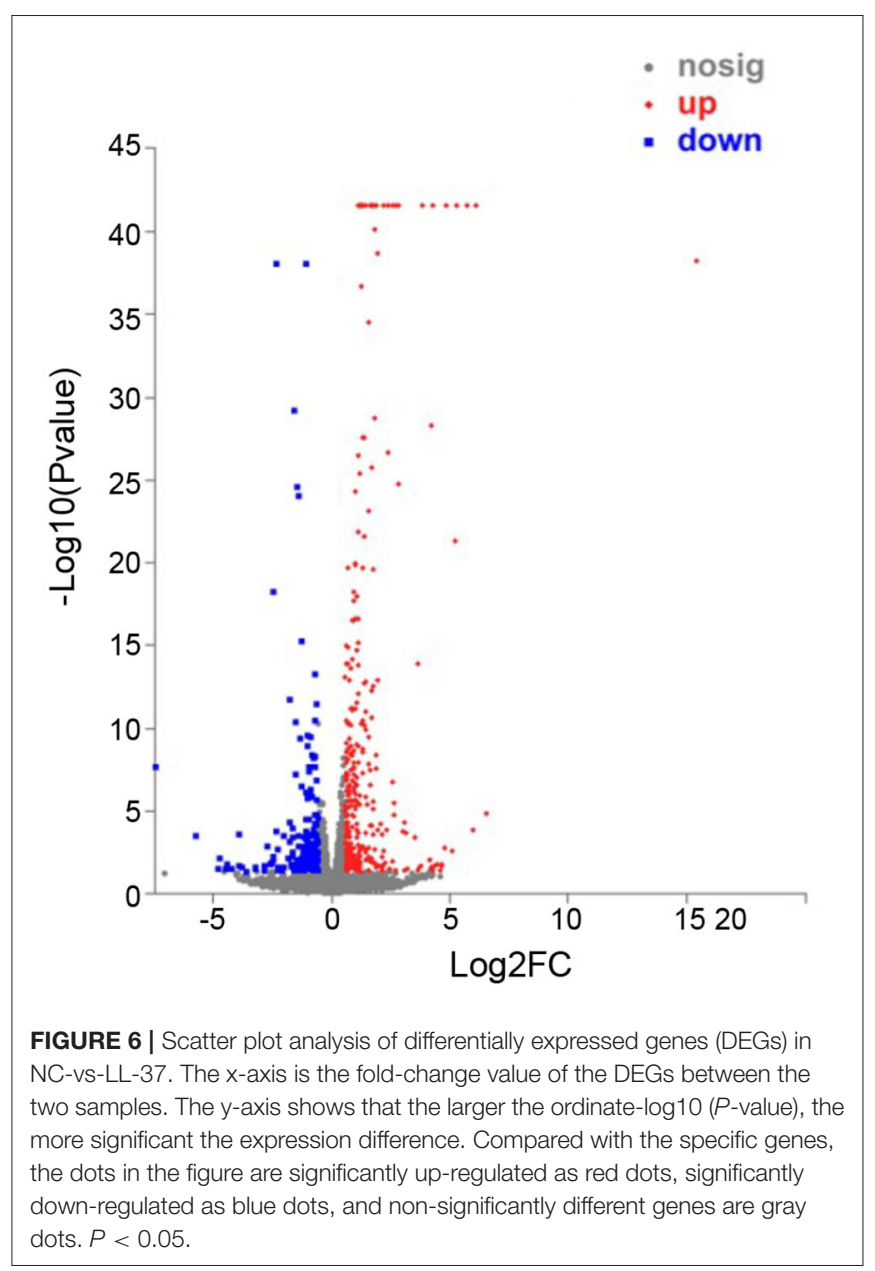

(10 mM, $3 \mathrm{~h})$. Then, cells in the four groups transfected with LL37 plasmids or with empty vectors $(1 \mu \mathrm{g}, 6 \mathrm{~h})$ were internalized with $P$. gingivalis (MOI 100, $6 \mathrm{~h}$ ) using the antibiotic protection assay, and the total RNA was extracted after $18 \mathrm{~h}$. The qRT-PCR result revealed that compared with that in the $\mathrm{NC}$ group, the number of $P$. gingivalis in the $3-\mathrm{MA}+\mathrm{NC}$ group was significantly decreased by $17.51 \%$ after the inhibition of autophagy, where $P$ $<0.05$. Moreover, the number of $P$. gingivalis in the $3-\mathrm{MA}+\mathrm{LL}-$ 37 group significantly increased by $162.57 \%$ after the inhibition of autophagy compared with that in the LL-37 group, where $P<$ 0.01 (Figure 5).

\section{DEGs Analysis}

In order to identify the biological process by which LL-37 may regulate autophagy, HaCaT cells were transfected and treated with $1 \mu \mathrm{g}$ of LL-37 plasmids or empty vectors for $24 \mathrm{~h}$ in triplicate. The total RNA of the HaCaT cells was extracted using the TRIzol UP reagent according to manufacturer's instructions. The Illumina HiSeq platform was used to undertake the highthroughput sequencing. As a result, we identified 650 DEGs between the cells transfected with LL-37 plasmids or empty vectors with fold changes of $\geq 2$ or $\leq 0.5$ and $P<0.05$, of which 374 genes were upregulated and $27 \overline{6}$ genes were downregulated 


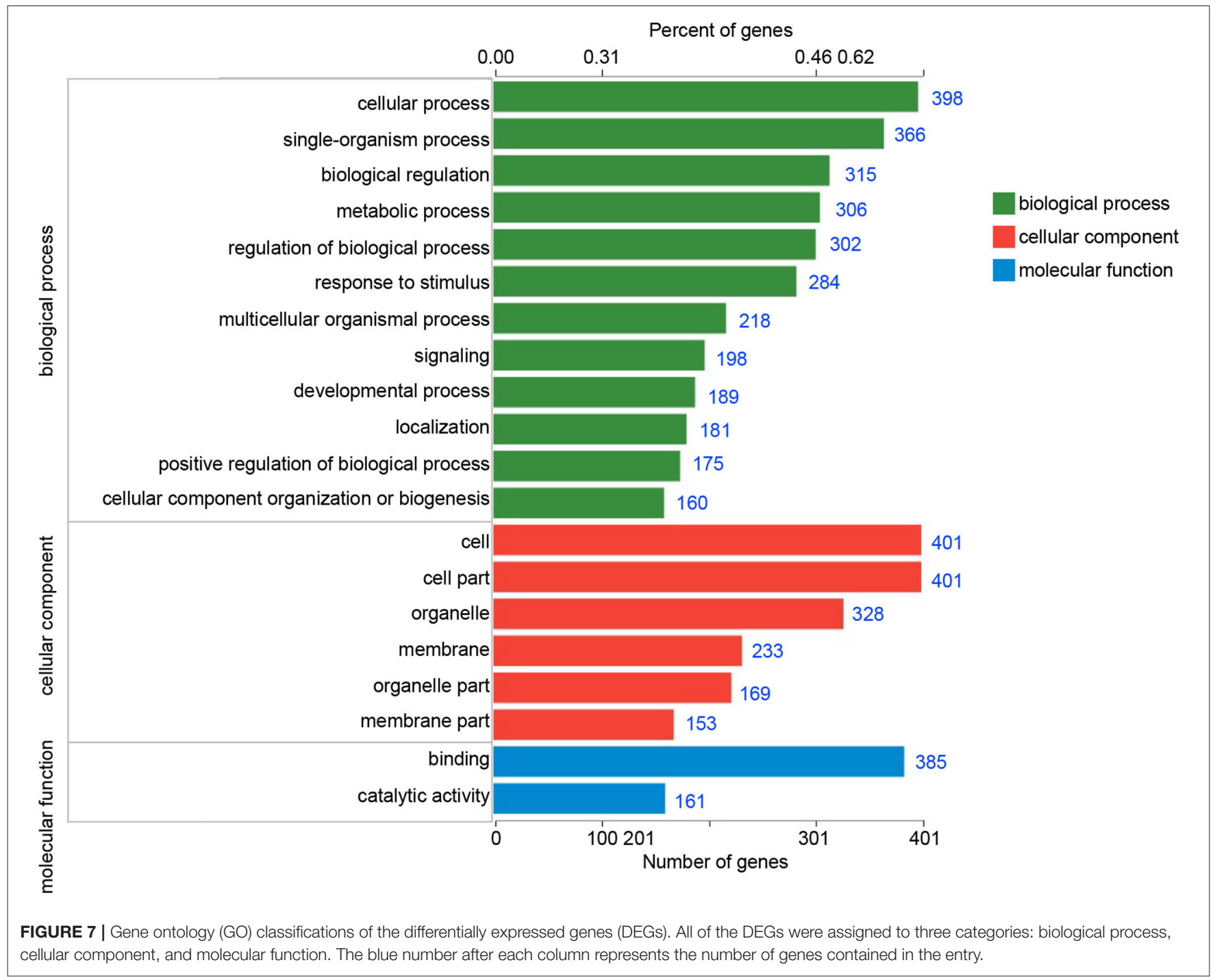

(Figure 6). GO assignments were used to assign a functional classification to these DEGs. All of the DEGs were annotated with 20 functional terms and categorized as a biological process, cellular component, or molecular function (Figure 7). COG was then used to assign a functional classification to these DEGs. After classification of the homology group database, U (Intracellular trafficking, secretion, and vesicular transport) was found to be the most representative functional cluster after $S$ (Function unknown) (Figure 8).

\section{DEGs Involved in Autophagy}

We identified six candidate autophagy-related genes from all DEGs based on GO enrichment analysis and the KEGG database (Table 2, Figure 9). The qRT-PCR assays conveyed that the relative expression levels of the tripartite motif-containing 22 (TRIM22) and lysosomal-associated membrane protein 3 (LAMP3) mRNA in cells treated with LL-37 plasmids were 3.76 and 2.44 times that of the control, respectively, with a statistical significance $P<0.05$.

\section{PPI Network Formation}

We investigated the connections between the CAMP and TRIM22/LAMP3 gene and their protein product (also labeled TRIM22/LAMP3) as well as the networks of TRIM22/LAMP3 and their interaction with autophagy. The PPI network constructed by Cytoscape is shown in Figure 10. The network included 26 nodes and 80 edges, and the yellow nodes represent the upregulated genes of the DEGs.

\section{DISCUSSION}

Studies have found that $P$. gingivalis can internalize in a variety of host cells and is closely related to the occurrence and development of a variety of systemic diseases (Gibson et al., 2004; Kozarov et al., 2005; Karnoutsos et al., 2008; Zaitsu et al., 


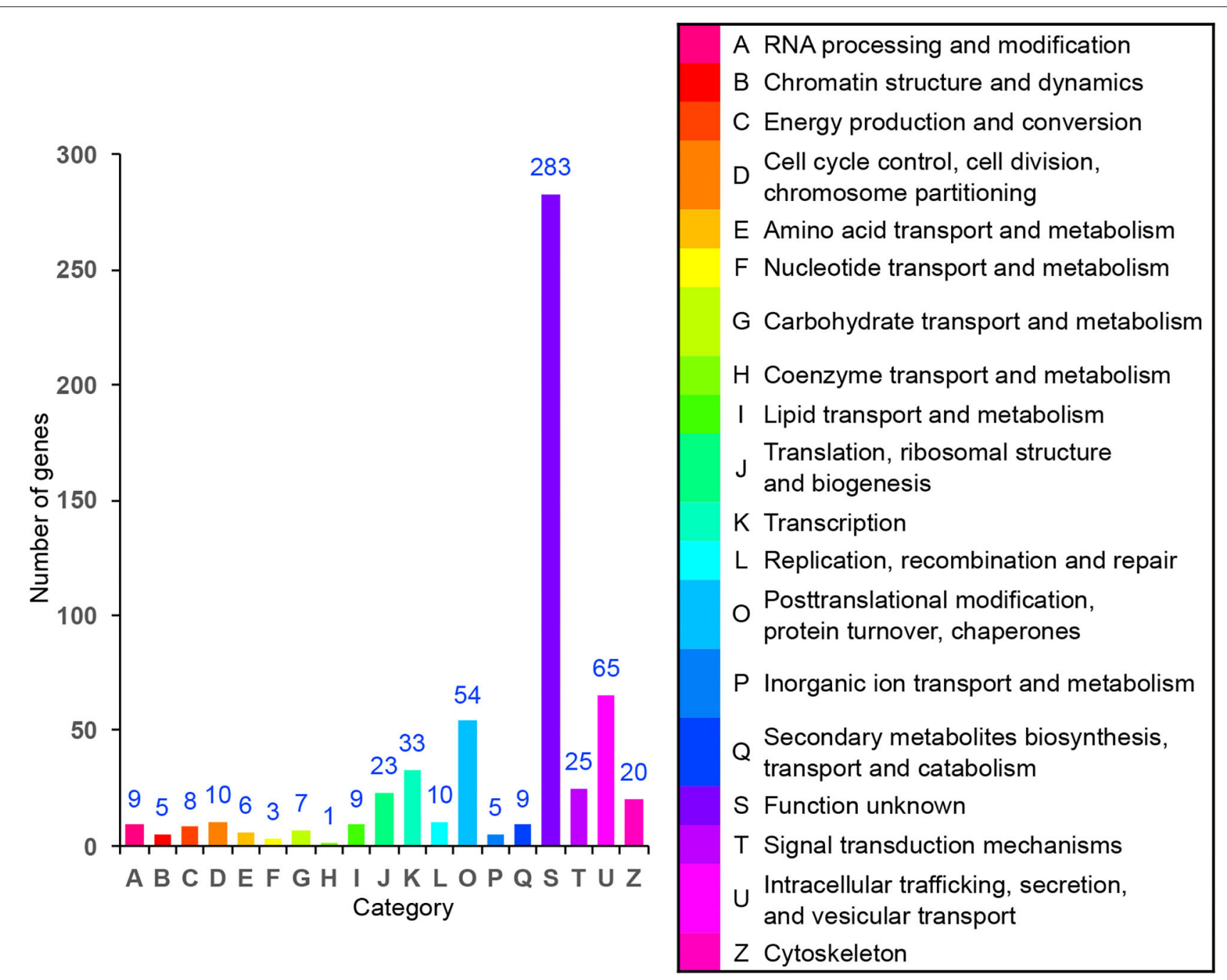

FIGURE 8 | Cluster of orthologous group (COG) assignment of the differentially expressed genes (DEGs). The vertical axis represents the number of DEGs in each category, and the horizontal axis represents the COG functional category.

TABLE 2 | Details of autophagy-related differentially expressed genes (DEGs).

\begin{tabular}{lcclc}
\hline Gene name & FCH (LL-37/NC) & $\boldsymbol{P}$ & Regulate & FCP (LL-37/NC) \\
\hline HIF1A-AS2 & 18.66 & 0.03 & Up & 1.40 \\
TRIM22 & 5.31 & 0.00 & Up & 3.76 \\
PRKCQ & 2.94 & 0.01 & Up & 1.81 \\
LAMP3 & 2.50 & 0.00 & Up & 2.44 \\
ATP6V1B1 & 0.30 & 0.00 & Down & 0.71 \\
IGBP1-AS1 & 0.06 & 0.03 & Down & 0.97
\end{tabular}

HaCaT cells were transfected and treated with $1 \mu \mathrm{g}$ of $L L-37$ plasmids (LL-37 group) or empty vectors (NC group) for $24 \mathrm{~h}$ in triplicate replicate. FCH (LL-37/NC): Fold changes of the DEGs between NC and LL-37 samples obtained by the high-throughput sequencing. FCP (LL-37/NC): Fold changes of the DEGs between NC and LL-37 samples detected by $q R T-P C R$.

2016). Therefore, antagonizing $P$. gingivalis in host cells is helpful to control periodontitis and systemic diseases. In this study, we first found that LL-37 can reduce the number of live $P$. gingivalis internalized in keratinocyte $\mathrm{HaCaT}$ cells by promoting autophagy.

First, this study revealed that overexpression of LL-37 decreased the quantity of viable $P$. gingivalis internalized in $\mathrm{HaCaT}$ cells in a dose-dependent manner. LL-37 has functions such as anti-pathogenic microorganism activity and immunomodulatory activity (Lin et al., 2015; Svensson et al., 2016; Jiang et al., 2018). It also exhibits a broad spectrum of antibacterial activity against most Gram-positive and Gramnegative bacteria (Vandamme et al., 2012). However, studies have indicated that $P$. gingivalis has low sensitivity and even resistance to LL-37 (Altman et al., 2006), potentially as a result of the degradation of LL-37 by the virulence factor of gingipains and the low affinity of $P$. gingivalis to LL-37 (Bachrach et al., 2008). Researchers have also found that LL-37 could inhibit the number of Mycobacterium tuberculosis by promoting autophagy in macrophages (Rekha et al., 2015; Wan et al., 2018). Therefore, we speculated that LL-37 could induce autophagy to degrade 


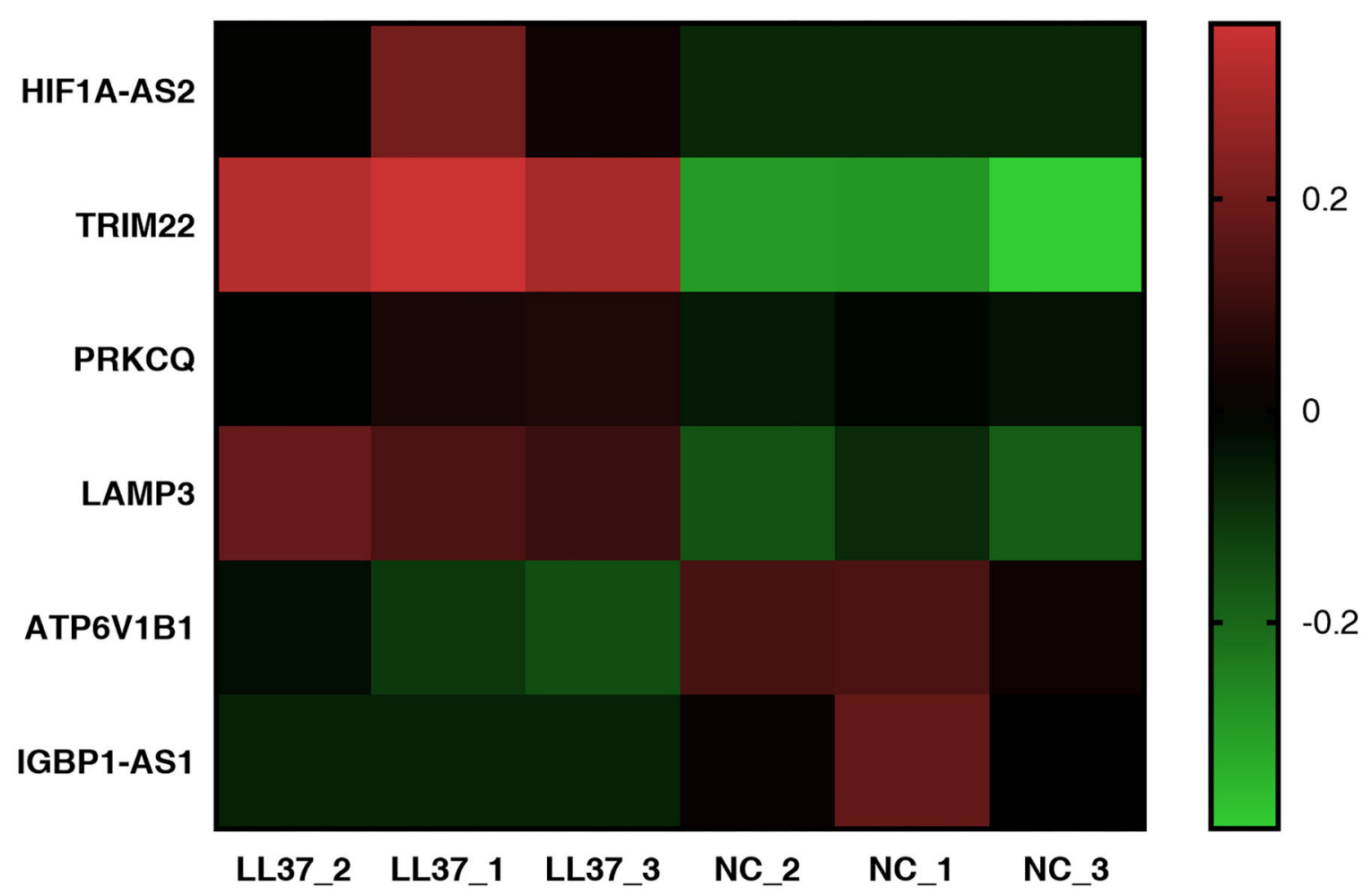

FIGURE 9 | Heat map of autophagy-related differentially expressed genes (DEGs). The heat map was completed using GraphPad Prism 7. The vertical axis represents an autophagy-related gene, and the horizontal axis represents a sample. Up-expression is represented in red, and down-expression is represented in green.

P. gingivalis in the keratinocyte, which has not been proved or elucidated by prior studies.

The results showed that $P$. gingivalis significantly promoted autophagy in a concentration- and time-dependent manner in the HaCaT cells. However, the number of live $P$. gingivalis decreased noticeably after the inhibition of autophagy by 3MA treatment. We therefore posit that autophagy may protect against the internalization of $P$. gingivalis in keratinocytes. Our previous study found that $P$. gingivalis could promote the formation of incomplete autophagosomes to protect them from elimination in non-phagocytes, such as epithelial cells, while $P$. gingivalis may induce functional autophagy in professional phagocytes, such as monocytes ( $\mathrm{Hu}$ et al., 2019). Similar to the results above, the findings of our study indicate that $P$. gingivalis may survive in the keratinocytes by promoting imperfect autophagy.

The results of this study also suggested that LL-37 can promote autophagy process to eliminate $P$. gingivalis in cells. Our study found that LL-37 could significantly induce autophagy by increasing the ratio of LC3-II/LC3-I and decreasing the expression of p62 in $\mathrm{HaCaT}$ cells with concentration and time dependencies. Similar results were reported by Rekha et al. (2015) and Yuk et al. (2009). In addition, LL-37 induced autophagy in $P$. gingivalis internalized $\mathrm{HaCaT}$ cells. However, after autophagy was inhibited by 3-MA, the bacteriostatic effect of LL-37 on $P$. gingivalis decreased significantly, indicating that LL-37 reduces the number of live $P$. gingivalis in $\mathrm{HaCaT}$ cells by promoting autophagy. As we mentioned above, $P$. gingivalis has low sensitivity or even resistance to LL-37 as a result of the degradation of LL-37 by the virulence factor of gingipains or the low affinity of $P$. gingivalis to LL-37 (Ouhara et al., 2005; Altman et al., 2006; Bachrach et al., 2008; Gutner et al., 2009). Furthermore, Puklo et al. found a $11-\mathrm{kDa}$ cathelicidin-derived fragment present in gingival crevicular fluid (GCF) that was collected from the pockets of patients with chronic periodontitis. This finding suggested that the bacterial proteases of $P$. gingivalis may degrade hCAP18/LL-37 to inhibit its antibacterial effect (Puklo et al., 2008). Therefore, we speculate that autophagy is a more important method by which LL-37 can inhibit the intercellular live $P$. gingivalis than direct bactericidal effects.

Furthermore, the transcriptome sequencing results indicated that LL-37 plays an important role in autophagy. The COG functional analysis was used to assign 65 DEGs to an "Intracellular trafficking, secretion, and vesicular transport" cluster. Vesicular transport is a cellular transport process by vesicle membranes. The inner membrane system refers to organelles surrounded by membrane structures including autophagosomes and lysosomes (Mellman and Warren, 2000; Bonifacino and Glick, 2004; Maxfield and van Meer, 2010). In addition, a GO analysis was used to assign DEGs into three main categories, in which "biological process" and "cellular component" were closely related to autophagy. Therefore, the COG functional analysis and GO analysis indicated the important roles of LL-37 in autophagy of HaCaT cells. 


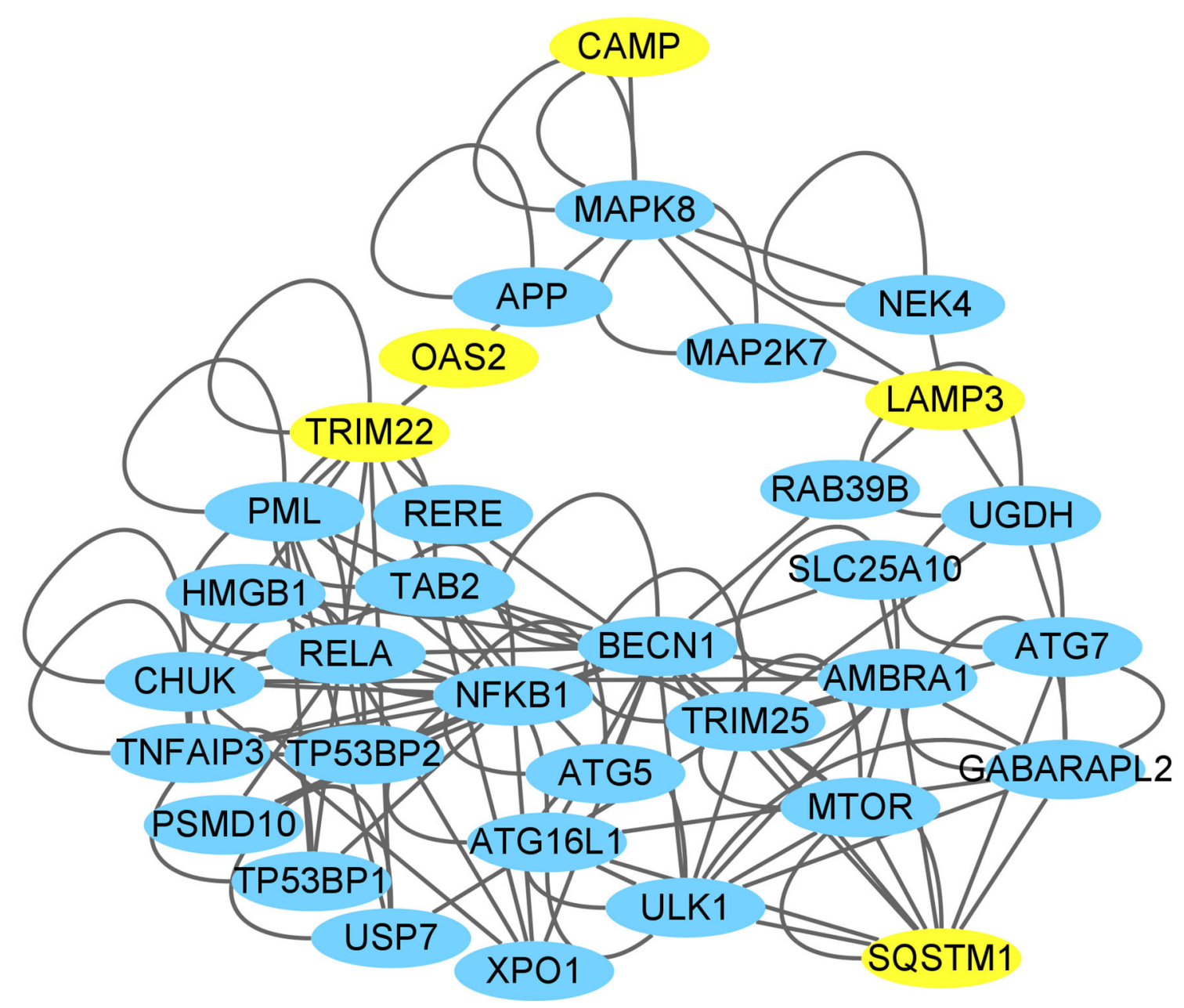

FIGURE 10 | CAMP interaction with autophagy network suggested by the Cytoscape. The yellow nodes represent the up-regulated genes of the DEGs through high-throughput sequencing analysis or verification by the present experiments (SQSTM1/p62).

The transcriptome sequencing results and qRT-PCR assays showed that the gene TRIM22 was significantly up-regulated in LL-37 treated cells. TRIM is involved in the regulation of almost all life activities (Tocchini and Ciosk, 2015). A large number of studies have found that TRIM can even regulate autophagy mechanism (Mandell et al., 2014; Kimura et al., 2015; Chauhan et al., 2016; Lou et al., 2018; Wang et al., 2018). As a member of the TRIM protein family, TRIM 22 has been proved to induce autophagy (Kimura et al., 2015; Lou et al., 2018). It is worth noting that the findings of Lou et al. indicated that TRIM22 can regulate autophagy of THP-1 cells by up-regulating the NF-кB/Beclin-1 pathway, and eliminate intracellular Mycobacterium tuberculosis by promoting autophagy (Lou et al., 2018). Also, it has been shown that LL37 can promote the expression of NF-кB (Suzuki et al., 2019) and the induction of transcription activity of NF- $\kappa \mathrm{B}$ (Lim et al., 2015). In the HaCaT cells, we speculated that LL-37 may induce autophagy by TRIM22/NF- $\kappa$ B/Beclin-1 pathway, which remains to be proved in future experiments.
In addition to TRIM22, LL-37 significantly up-regulated the expression of gene LAMP3. LAMP3 is the third member of the LAMP family (de Saint-Vis et al., 1998) and plays a vital role in autophagy (Tanaka et al., 2000; Eskelinen et al., 2002). The LAMP protein is thought to be involved in the fusion of autophagosomes and lysosomes into autophagolysosomes (Tanaka et al., 2000; Zheng et al., 2011). Nagelkerke et al. indicated that LAMP3 is localized to the lysosomal membrane and is involved in the fusion of autophagosomes and lysosomes in breast cancer cells. After LAMP3 knockout, autophagy was suppressed (Nagelkerke et al., 2014). In a future study, we will try to explore the potential LAMP3-associated pathway through which LL-37 induces autophagy in keratinocytes.

The PPI network showed that CAMP could interact with the proteins translated from the up-regulated genes TRIM22/LAMP3 through MAPK8. It is worth noting that the KEGG enrichment analysis revealed the MAPK signaling pathway as one of the most significantly enriched pathways in our study. Furthermore, in this network, some molecules have been reported to be regulated 
by TRIM22 and LAMP3 to promote autophagy, such as NF- $\kappa$ B, Beclin-1, and Atg 5 (Wang et al., 2011; Takaesu et al., 2012; Qiu et al., 2013; Seto et al., 2013; Huttlin et al., 2017). However, most molecules in the predicted network are not the DEGs identified in our study. The other possible reason may be that the related molecules could promote autophagy by their enhanced functions (such as an increase in phosphorylation efficiency) rather than by expression level changes.

The limitation of this experiment was that LL-37 knockdown was not performed on $\mathrm{HaCaT}$ cells. The main reason was the low expression of endogenous LL-37 in HaCaT cells, which has been supported by other studies (Svensson et al., 2016; Jiang et al., 2018; López-González et al., 2018; Suhng et al., 2018). In addition, cells that were transfected with LL-37 plasmids could not suppress the expression by knockdown. At present, there are no effective antagonists or neutralizing antibodies of LL-37 to antagonize the effect of LL-37. Therefore, cell lines with a high expression of endogenous LL-37 should be screened in a future study. In addition, the related molecular pathway of LL-37induced autophagy during the $P$. gingivalis elimination process should be explored further.

In conclusion, our findings indicated that LL-37 can reduce the number of live $P$. gingivalis internalized in keratinocytes by promoting autophagy. The prediction of transcriptome sequencing and the verification assay suggested that LL-37 plays an important role in autophagy and might promote autophagy of keratinocytes by regulating TRIM22 and LAMP3. This study provides scientific clues about the role and potential application of LL-37 in the elimination of $P$. gingivalis

\section{REFERENCES}

Alanis-Lobato, G., Andrade-Navarro, M. A., and Schaefer, M. H. (2017). HIPPIE v2.0: enhancing meaningfulness and reliability of protein-protein interaction networks. Nucl. Acids Res. 45, D408-D414. doi: 10.1093/nar/gkw985

Altman, H., Steinberg, D., Porat, Y., Mor, A., Fridman, D., Friedman, M., et al. (2006). In vitro assessment of antimicrobial peptides as potential agents against several oral bacteria. J. Antimicrob. Chemother. 58, 198-201. doi: $10.1093 / \mathrm{jac} / \mathrm{dkl} 181$

Bachrach, G., Altman, H., Kolenbrander, P. E., Chalmers, N. I., Gabai-Gutner, M., Mor, A., et al. (2008). Resistance of Porphyromonas gingivalis ATCC 33277 to direct killing by antimicrobial peptides is protease independent. Antimicrob. Agents Chemother. 52, 638-642. doi: 10.1128/AAC.01271-07

Bonifacino, J. S., and Glick, B. S. (2004). The mechanisms of vesicle budding and fusion. Cell 116, 153-166. doi: 10.1016/S0092-8674(03)01079-1

Burton, M. F., and Steel, P. G. (2009). The chemistry and biology of LL-37. Nat. Prod. Rep. 26, 1572-1584. doi: 10.1039/b912533g

Chang, C., Geng, F., Shi, X., Li, Y., Zhang, X., Zhao, X., et al. (2019a). The prevalence rate of periodontal pathogens and its association with oral squamous cell carcinoma. Appl. Microbiol. Biotechnol. 103, 1393-1404. doi: 10.1007/s00253-018-9475-6

Chang, C., Wang, H., Liu, J., Pan, C., Zhang, D., Li, X., et al. (2019b). Porphyromonas gingivalis infection promoted the proliferation of oral squamous cell carcinoma cells through the miR-21/PDCD4/AP1 negative signaling pathway. ACS Infect. Dis. 5, 1336-1347. doi: 10.1021/acsinfecdis.9b00032

Chauhan, S., Kumar, S., Jain, A., Ponpuak, M., Mudd, M. H., Kimura, T., et al. (2016). TRIMs and Galectins globally cooperate and TRIM16 and Galectin3 co-direct autophagy in endomembrane damage homeostasis. Dev. Cell 39, 13-27. doi: 10.1016/j.devcel.2016.08.003 in keratinocytes, and in turn, it can be used to develop methods for the prevention of periodontitis treatment of associated diseases.

\section{DATA AVAILABILITY STATEMENT}

The RNA-seq data has been submitted to SRA database in NCBI, BioProject number PRJNA663720, accessions SRR12649922 SRR12649927.

\section{AUTHOR CONTRIBUTIONS}

XT, YP, XF, JL, YG, and XY designed the study. XY performed the experiments with the help from XT. JL, YG, LN, FG, and XY wrote the final manuscript. XT, YP, XF, LN, CP, and YG revised the manuscript. All authors contributed to the article and approved the submitted version.

\section{FUNDING}

The present work was supported by the National Natural Science Foundation of China (81670999) and Shenyang Youth Science and Technology Innovation Talent Support Project supported by Shenyang Science and Technology Bureau (RC170520).

\section{ACKNOWLEDGMENTS}

We thank LetPub (www.letpub.com) for its linguistic assistance during the preparation of this manuscript.

de Camargo Pereira, G., Guimarães, G. N., Planello, A. C., Santamaria, M. P., de Souza, A. P., Line, S. R., et al. (2013). Porphyromonas gingivalis LPS stimulation downregulates DNMT1, DNMT3a, and JMJD3 gene expression levels in human HaCaT keratinocytes. Clin. Oral Investig. 17, 1279-1285. doi: 10.1007/s00784-012-0816-z

de Saint-Vis, B., Vincent, J., Vandenabeele, S., Vanbervliet, B., Pin, J. J., Aitt-Yahia, S., et al. (1998). A novel lysosome-associated membrane glycoprotein, DCLAMP, induced upon DC maturation, is transiently expressed in MHC class II compartment. Immunity 9, 325-336. doi: 10.1016/S1074-7613(00)80615-9

Dorschner, R. A., Pestonjamasp, V. K., Tamakuwala, S., Ohtake, T., Rudisill, J., Nizet, V., et al. (2001). Cutaneous injury induces the release of cathelicidin antimicrobial peptides active against group A Streptococcus. J. Invest. Dermatol. 117, 91-97. doi: 10.1046/j.1523-1747.2001.01340.x

Eick, S., Seltmann, T., and Pfister, W. (2004). Efficacy of antibiotics to strains of periodontopathogenic bacteria within a single species biofilm - an in vitro study. J. Clin. Periodontol. 31, 376-383. doi: 10.1111/j.0303-6979.2004.00490.x

Eskelinen, E. L., Illert, A. L., Tanaka, Y., Schwarzmann, G., Blanz, J., Von Figura, K., et al. (2002). Role of LAMP-2 in lysosome biogenesis and autophagy. Mol. Biol. Cell 13, 3355-3368. doi: 10.1091/mbc.e02-02-0114

Geng, F., Wang, Q., Li, C., Liu, J., Zhang, D., Zhang, S., et al. (2019). Identification of potential candidate genes of oral cancer in response to chronic infection with Porphyromonas gingivalis using bioinformatical analyses. Front. Oncol. 9:91. doi: $10.3389 /$ fonc. 2019.00091

Gibson, F. C. 3rd, Hong, C., Chou, H. H., Yumoto, H., Chen, J., Lien, E., et al. (2004). Innate immune recognition of invasive bacteria accelerates atherosclerosis in apolipoprotein E-deficient mice. Circulation 109, 2801-2806. doi: 10.1161/01.CIR.0000129769.17895.F0

Grossi, S. G., Genco, R. J., Machtei, E. E., Ho, A. W., Koch, G., Dunford, R., et al. (1995). Assessment of risk for periodontal disease. II. Risk indicators for alveolar bone loss. J. Periodontol. 66, 23-29. doi: 10.1902/jop.1995.66.1.23 
Gutner, M., Chaushu, S., Balter, D., and Bachrach, G. (2009). Saliva enables the antimicrobial activity of LL-37 in the presence of proteases of Porphyromonas gingivalis. Infect. Immun. 77, 5558-5563. doi: 10.1128/IAI.00648-09

Hase, K., Murakami, M., Iimura, M., Cole, S. P., Horibe, Y., Ohtake, T., et al. (2003). Expression of LL-37 by human gastric epithelial cells as a potential host defense mechanism against Helicobacter pylori. Gastroenterology 125, 1613-1625. doi: 10.1053/j.gastro.2003.08.028

Holt, S. C., and Ebersole, J. L. (2005). Porphyromonas gingivalis, Treponema denticola, and Tannerella forsythia: the "red complex", a prototype polybacterial pathogenic consortium in periodontitis. Periodontol 2000 38, 72-122. doi: 10.1111/j.1600-0757.2005.00113.x

Hu, X., Niu, L., Ma, C., Huang, Y., Yang, X., Shi, Y., et al. (2019). Calcitriol decreases live Porphyromonas gingivalis internalized into epithelial cells and monocytes by promoting autophagy. J. Periodontol. 91, 956-966. doi: 10.1002/JPER.19-0510

Huttlin, E. L., Bruckner, R. J., Paulo, J. A., Cannon, J. R., Ting, L., Baltier, K., et al. (2017). Architecture of the human interactome defines protein communities and disease networks. Nature 545, 505-509. doi: 10.1038/nature22366

Imai, K., Ochiai, K., and Okamoto, T. (2009). Reactivation of latent HIV-1 infection by the periodontopathic bacterium Porphyromonas gingivalis involves histone modification. J. Immunol. 182, 3688-3695. doi: 10.4049/jimmunol.0802906

Jiang, J., Zhang, Y., Indra, A. K., Ganguli-Indra, G., Le, M. N., Wang, H., et al. (2018). 1 $\alpha, 25$-dihydroxyvitamin $\mathrm{D}_{3}$-eluting nanofibrous dressings induce endogenous antimicrobial peptide expression. Nanomedicine 13, 1417-1432. doi: 10.2217/nnm-2018-0011

Karnoutsos, K., Papastergiou, P., Stefanidis, S., and Vakaloudi, A. (2008). Periodontitis as a risk factor for cardiovascular disease: the role of antiphosphorylcholine and anti-cardiolipin antibodies. Hippokratia 12, 144-149.

Kidwai, F. K., Jokhun, D. S., Movahednia, M. M., Yeo, J. F., Tan, K. S., and Cao, T. (2013). Human embryonic stem cells derived keratinocyte as an in vitro research model for the study of immune response. J. Oral Pathol. Med. 42, 627-634. doi: 10.1111/jop.12054

Kim, W. H., An, H. J., Kim, J. Y., Gwon, M. G., Gu, H., Jeon, M., et al. (2018). Anti-inflammatory effect of melittin on Porphyromonas gingivalis LPSstimulated human keratinocytes. Molecules 23:332. doi: 10.3390/molecules230 20332

Kimura, T., Jain, A., Choi, S. W., Mandell, M. A., Schroder, K., Johansen, T., et al. (2015). TRIM-mediated precision autophagy targets cytoplasmic regulators of innate immunity. J. Cell Biol. 210, 973-989. doi: 10.1083/jcb.201503023

Kozarov, E. V., Dorn, B. R., Shelburne, C. E., Dunn, W. A. Jr, and Progulske-Fox, A. (2005). Human atherosclerotic plaque contains viable invasive Actinobacillus actinomycetemcomitans and Porphyromonas gingivalis. Arterioscler. Thromb. Vasc. Biol. 25, e17-e18. doi: 10.1161/01.ATV.0000155018.67835.1a

Lamont, R. J., Chan, A., Belton, C. M., Izutsu, K. T., Vasel, D., and Weinberg, A. (1995). Porphyromonas gingivalis invasion of gingival epithelial cells. Infect. Immun. 63, 3878-3885. doi: 10.1128/IAI.63.10.3878-3885.1995

Lapierre, L. R., Gelino, S., Meléndez, A., and Hansen, M. (2011). Autophagy and lipid metabolism coordinately modulate life span in germline-less C. elegans. Curr. Biol. 21, 1507-1514. doi: 10.1016/j.cub.2011.07.042

Larrick, J. W., Hirata, M., Balint, R. F., Lee, J., Zhong, J., and Wright, S. C. (1995). Human CAP18: a novel antimicrobial lipopolysaccharide-binding protein. Infect. Immun. 63, 1291-1297. doi: 10.1128/IAI.63.4.1291-1297.1995

Lim, R., Barker, G., and Lappas, M. (2015). Human cathelicidin antimicrobial protein 18 (hCAP18/LL-37) is increased in foetal membranes and myometrium after spontaneous labour and delivery. J. Reprod. Immunol. 107, 31-42. doi: $10.1016 /$ j.jri.2014.10.002

Lin, M., Tsai, P. W., Chen, J., Lin, Y. Y., and Lan, C. Y. (2015). OmpA binding mediates the effect of antimicrobial peptide LL-37 on acinetobacter baumannii. PLoS ONE 10:e0141107. doi: 10.1371/journal.pone.0141107

Löfmark, S., Edlund, C., and Nord, C. E. (2010). Metronidazole is still the drug of choice for treatment of anaerobic infections. Clin. Infect. Dis. 1, S16-S23. doi: 10.1086/647939

López-González, M., Meza-Sánchez, D., García-Cordero, J., Bustos-Arriaga, J., Vélez-Del Valle, C., Marsch-Moreno, M., et al. (2018). Human keratinocyte cultures $(\mathrm{HaCaT})$ can be infected by DENV, triggering innate immune responses that include IFN $\lambda$ and LL37. Immunobiology 223, 608-617. doi: 10.1016/j.imbio.2018.07.006
Lou, J., Wang, Y., Zheng, X., and Qiu, W. (2018). TRIM22 regulates macrophage autophagy and enhances Mycobacterium tuberculosis clearance by targeting the nuclear factor-multiplicity kappaB/beclin 1 pathway. J. Cell. Biochem. 119, 8971-8980. doi: $10.1002 /$ jcb. 27153

Mandell, M. A., Jain, A., Arko-Mensah, J., Chauhan, S., Kimura, T., Dinkins, C., et al. (2014). TRIM proteins regulate autophagy and can target autophagic substrates by direct recognition. Dev. Cell 30, 394-409. doi: 10.1016/j.devcel.2014.06.013

Mantri, C. K., Chen, C., Dong, X., Goodwin, J. S., and Xie, H. (2014). Porphyromonas gingivalis -mediated epithelial cell entry of HIV-1. J. Dent. Res. 93, 794-800. doi: 10.1177/0022034514537647

Maxfield, F. R., and van Meer, G. (2010). Cholesterol, the central lipid of mammalian cells. Curr. Opin. Cell Biol. 22, 422-429. doi: $10.1016 /$ j.ceb.2010.05.004

Mellman, I., and Warren, G. (2000). The road taken: past and future foundations of membrane traffic. Cell 100, 99-112. doi: 10.1016/S0092-8674(00)81687-6

Nagelkerke, A., Sieuwerts, A. M., Bussink, J., Sweep, F. C., Look, M. P., Foekens, J. A., et al. (2014). LAMP3 is involved in tamoxifen resistance in breast cancer cells through the modulation of autophagy. Endocr. Relat. Cancer 21, 101-112. doi: 10.1530/ERC-13-0183

Oughtred, R., Stark, C., Breitkreutz, B. J., Rust, J., Boucher, L., Chang, C., et al. (2019). The BioGRID interaction database: 2019 update. Nucl. Acids Res. 47, D529-D541. doi: 10.1093/nar/gky1079

Ouhara, K., Komatsuzawa, H., Yamada, S., Shiba, H., Fujiwara, T., Ohara, M., et al. (2005). Susceptibilities of periodontopathogenic and cariogenic bacteria to antibacterial peptides, \{beta\}-defensins and LL37, produced by human epithelial cells. J. Antimicrob. Chemother. 55, 888-896. doi: 10.1093/jac/ dki103

Pan, C., Xu, X., Tan, L., Lin, L., and Pan, Y. (2014). The effects of Porphyromonas gingivalis on the cell cycle progression of human gingival epithelial cells. Oral Dis. 20, 100-108. doi: 10.1111/odi.12081

Park, M. H., Jeong, S. Y., Na, H. S., and Chung, J. (2017). Porphyromonas gingivalis induces autophagy in THP-1-derived macrophages. Mol. Oral Microbiol. 32, 48-59. doi: 10.1111/omi.12153

Pillich, R. T., Chen, J., Rynkov, V., Welker, D., and Pratt, D. (2017). NDEx: a community resource for sharing and publishing of biological networks. Methods Mol. Biol. 1558, 271-301. doi: 10.1007/978-1-4939-6783-4_13

Pratt, D., Chen, J., Welker, D., Rivas, R., Pillich, R., Rynkov, V., et al. (2015). NDEx, the network data exchange. Cell Syst. 1, 302-305. doi: 10.1016/j.cels.2015.10.001

Puklo, M., Guentsch, A., Hiemstra, P. S., Eick, S., and Potempa, J. (2008). Analysis of neutrophil-derived antimicrobial peptides in gingival crevicular fluid suggests importance of cathelicidin LL-37 in the innate immune response against periodontogenic bacteria. Oral Microbiol. Immunol. 23, 328-335. doi: 10.1111/j.1399-302X.2008.00433.x

Qiu, H., Huang, F., Xiao, H., Sun, B., and Yang, R. (2013). TRIM22 inhibits the TRAF6-stimulated NF-кB pathway by targeting TAB2 for degradation. Virol. Sin. 28, 209-215. doi: 10.1007/s12250-013-3343-4

Rekha, R. S., Rao Muvva, S. S., Wan, M., Raqib, R., Bergman, P., Brighenti, S., et al. (2015). Phenylbutyrate induces LL-37-dependent autophagy and intracellular killing of Mycobacterium tuberculosis in human macrophages. Autophagy 11, 1688-1699. doi: 10.1080/15548627.2015.1075110

Sanjuan, M. A., and Green, D. R. (2008). Eating for good health: linking autophagy and phagocytosis in host defense. Autophagy 4, 607-611. doi: 10.4161/auto.6397

Seto, S., Sugaya, K., Tsujimura, K., Nagata, T., Horii, T., and Koide, Y. (2013). Rab39a interacts with phosphatidylinositol 3-kinase and negatively regulates autophagy induced by lipopolysaccharide stimulation in macrophages. PLoS ONE 8:e83324. doi: 10.1371/journal.pone.0083324

Shah, H. N., and Collins, M. D. (1988). Proposal for reclassification of bacteroides asaccharolyticus, bacteroides gingivalis, and bacteroides endodontalis in a new genus, porphyromonas. Int. J. Syst. Bacteriol. 38, 128-131. doi: 10.1099/00207713-38-1-128

Shannon, P., Markiel, A., Ozier, O., Baliga, N. S., Wang, J. T., Ramage, D., et al. (2003). Cytoscape: a software environment for integrated models of biomolecular interaction networks. Genome Res. 13, 2498-2504. doi: 10.1101/gr.1239303

Soares, G. M., Figueiredo, L. C., Faveri, M., Cortelli, S. C., Duarte, P. M., and Feres, M. (2012). Mechanisms of action of systemic antibiotics used in periodontal 
treatment and mechanisms of bacterial resistance to these drugs. J. Appl. Oral Sci. 20, 295-309. doi: 10.1590/S1678-77572012000300002

Socransky, S. S., and Haffajee, A. D. (1992). The bacterial etiology of destructive periodontal disease: current concepts. J Periodontol. 63, 322-331. doi: 10.1902/jop.1992.63.4s.322

Suhng, E., Kim, B. H., Choi, Y. W., Choi, H. Y., Cho, H., and Byun, J. Y. (2018). Increased expression of IL-33 in rosacea skin and UVB-irradiated and LL-37treated HaCaT cells. Exp. Dermatol. 27, 1023-1029. doi: 10.1111/exd.13702

Suzuki, K., Ohkuma, M., and Nagaoka, I. (2019). Bacterial lipopolysaccharide and antimicrobial LL-37 enhance ICAM-1 expression and NF-kappaB p65 phosphorylation in senescent endothelial cells. Int. J. Mol. Med. 44, 1187-1196. doi: $10.3892 / \mathrm{ijmm} .2019 .4294$

Svensson, D., Nebel, D., Voss, U., Ekblad, E., and Nilsson, B. O. (2016). Vitamin D-induced up-regulation of human keratinocyte cathelicidin anti-microbial peptide expression involves retinoid X receptor $\alpha$. Cell Tissue Res. 366, 353-362. doi: 10.1007/s00441-016-2449-z

Szklarczyk, D., Morris, J. H., Cook, H., Kuhn, M., Wyder, S., Simonovic, M., et al. (2017). The STRING database in 2017: quality-controlled protein-protein association networks, made broadly accessible. Nucl. Acids Res. 45, D362-D368. doi: 10.1093/nar/gkw937

Takaesu, G., Kobayashi, T., and Yoshimura, A. (2012). TGFß-activated kinase 1 (TAK1)-binding proteins (TAB) 2 and 3 negatively regulate autophagy. $J$. Biochem. 151, 157-166. doi: 10.1093/jb/mvr123

Tanaka, Y., Guhde, G., Suter, A., Eskelinen, E. L., Hartmann, D., Lüllmann-Rauch, R., et al. (2000). Accumulation of autophagic vacuoles and cardiomyopathy in LAMP-2-deficient mice. Nature 406, 902-906. doi: 10.1038/35022595

Tocchini, C., and Ciosk, R. (2015). TRIM-NHL proteins in development and disease. Semin. Cell Dev. Biol. 47-48, 52-59. doi: 10.1016/j.semcdb.2015.10.017

Turner, J., Cho, Y., Dinh, N. N., Waring, A. J., and Lehrer, R. I. (1998). Activities of LL-37, a cathelin-associated antimicrobial peptide of human neutrophils. Antimicrob. Agents Chemother. 42, 2206-2214. doi: 10.1128/AAC.42.9.2206

Vandamme, D., Landuyt, B., Luyten, W., and Schoofs, L. (2012). A comprehensive summary of LL-37, the factotum human cathelicidin peptide. Cell. Immunol. 280, 22-35. doi: 10.1016/j.cellimm.2012.11.009

Wan, M., Tang, X., Rekha, R. S., Muvva, S., Brighenti, S., Agerberth, B., et al. (2018). Prostaglandin E2 suppresses hCAP18/LL-37 expression in human macrophages via EP2/EP4: implications for treatment of Mycobacterium tuberculosis infection. FASEB J. 32, 2827-2840. doi: 10.1096/fj. 201701308
Wang, G., Watson, K. M., and Jr. Buckheit, R. W. (2008). Anti-human immunodeficiency virus type 1 activities of antimicrobial peptides derived from human and bovine cathelicidins. Antimicrob. Agents Chemother. 52, 3438-3440. doi: 10.1128/AAC.00452-08

Wang, J., Huo, K., Ma, L., Tang, L., Li, D., Huang, X., et al. (2011). Toward an understanding of the protein interaction network of the human liver. Mol. Syst. Biol. 7:536. doi: 10.1038/msb.2011.67

Wang, W., Xia, Z., Farre, J. C., and Subramani, S. (2018). TRIM37 deficiency induces autophagy through deregulating the MTORC1-TFEB axis. Autophagy 14, 1574-1585. doi: 10.1080/15548627.2018.1463120

Weidberg, H., Shvets, E., and Elazar, Z. (2011). Biogenesis and cargo selectivity of autophagosomes. Annu. Rev. Biochem. 80, 125-156. doi: 10.1146/annurev-biochem-052709-094552

Yilmaz, O., Verbeke, P., Lamont, R. J., and Ojcius, D. M. (2006). Intercellular spreading of Porphyromonas gingivalis infection in primary gingival epithelial cells. Infect. Immun. 74, 703-710. doi: 10.1128/IAI.74.1.703-710.2006

Yuk, J. M., Shin, D. M., Lee, H. M., Yang, C. S., Jin, H. S., Kim, K. K., et al. (2009). Vitamin D3 induces autophagy in human monocytes/macrophages via cathelicidin. Cell Host Microbe 6, 231-243. doi: 10.1016/j.chom.2009.08.004

Zaitsu, Y., Iwatake, M., Sato, K., and Tsukuba, T. (2016). Lipid droplets affect elimination of Porphyromonas gingivalis in HepG2 cells by altering the autophagy-lysosome system. Microbes Infect. 18, 565-571. doi: 10.1016/j.micinf.2016.05.004

Zheng, L., Terman, A., Hallbeck, M., Dehvari, N., Cowburn, R. F., Benedikz, E., et al. (2011). Macroautophagy-generated increase of lysosomal amyloid betaprotein mediates oxidant-induced apoptosis of cultured neuroblastoma cells. Autophagy 7, 1528-1545. doi: 10.4161/auto.7.12.18051

Conflict of Interest: The authors declare that the research was conducted in the absence of any commercial or financial relationships that could be construed as a potential conflict of interest.

Copyright $\odot 2020$ Yang, Niu, Pan, Feng, Liu, Guo, Pan, Geng and Tang. This is an open-access article distributed under the terms of the Creative Commons Attribution License (CC BY). The use, distribution or reproduction in other forums is permitted, provided the original author(s) and the copyright owner(s) are credited and that the original publication in this journal is cited, in accordance with accepted academic practice. No use, distribution or reproduction is permitted which does not comply with these terms. 